\title{
Locus Ceruleus Degeneration Promotes Alzheimer Pathogenesis in Amyloid Precursor Protein 23 Transgenic Mice
}

\author{
Michael T. Heneka, ${ }^{1}$ Mutiah Ramanathan, ${ }^{1}$ Andreas H. Jacobs, ${ }^{3}$ Lucia Dumitrescu-Ozimek, ${ }^{1}$ Andras Bilkei-Gorzo, ${ }^{2}$ \\ Thomas Debeir, ${ }^{4}$ Magdalena Sastre, ${ }^{1}$ Norbert Galldiks, ${ }^{3}$ Andreas Zimmer, ${ }^{2}$ Mathias Hoehn, ${ }^{3}$ Wolf-Dieter Heiss, ${ }^{3}$ \\ Thomas Klockgether, ${ }^{1}$ and Matthias Staufenbiel ${ }^{5}$ \\ Departments of ${ }^{1}$ Neurology and ${ }^{2}$ Psychiatry, University of Bonn, 53127 Bonn, Germany, ${ }^{3}$ Max Planck Institute for Neurological Research, Department of \\ Neurology and Center for Molecular Medicine, University of Cologne, 50931 Cologne, Germany, ${ }^{4}$ National Institute of Health and of Medical Research Unit \\ 679, Neurology and Experimental Therapeutics, Salpêtrière Hospital, 75651 Paris, France, and ${ }^{5}$ Novartis Institutes for Biomedical Research Basel, 4002 \\ Basel, Switzerland
}

Locus ceruleus (LC) degeneration and loss of cortical noradrenergic innervation occur early in Alzheimer's disease (AD). Although this has been known for several decades, the contribution of LC degeneration to AD pathogenesis remains unclear. We induced LC degeneration with $N$-(2-chloroethyl)- $N$-ethyl-bromo-benzylamine (dsp4) in amyloid precursor protein 23 (APP23) transgenic mice with a low amyloid load. Then 6 months later the LC projection areas showed a robust elevation of glial inflammation along with augmented amyloid plaque deposits. Moreover, neurodegeneration and neuronal loss significantly increased. Importantly, the paraventricular thalamus, a nonprojection area, remained unaffected. Radial arm maze and social partner recognition tests revealed increased memory deficits while high-resolution magnetic resonance imaging-guided micro-positron emission tomography demonstrated reduced cerebral glucose metabolism, disturbed neuronal integrity, and attenuated acetylcholinesterase activity. Nontransgenic mice with LC degeneration were devoid of these alterations. Our data demonstrate that the degeneration of LC affects morphology, metabolism, and function of amyloid plaque-containing higher brain regions in APP23 mice. We postulate that LC degeneration substantially contributes to AD development.

Key words: degeneration; neuroinflammation; microglia; astroglia; locus ceruleus; neuronal death

\section{Introduction}

Locus ceruleus (LC) degeneration is an early and well described feature of Alzheimer's disease (AD) (Forno, 1966; German et al., 1992). The LC serves as main source of noradrenergic innervation to various cortical areas, including the hippocampus, entorhinal, and frontal cortex. LC degeneration and the subsequent loss of arising axons result in decreased noradrenaline (NA) levels in respective brain regions of AD patients (Adolfsson et al., 1979; Mann et al., 1980; Matthews et al., 2002). The reduction of LC neurons correlates with amyloid- $\beta(\mathrm{A} \beta)$ plaques, neurofibrillary tangles, and the severity of dementia (Bondareff et al., 1987). LC neurons also show ectopic expression of cell cycle proteins predictive of cell death (Busser et al., 1998). Loss of LC neurons was found to be more extensive and to correlate better with the duration of $\mathrm{AD}$ than cholinergic cell loss of the nucleus basalis of Meynert (Forstl et al., 1994; Zarow et al., 2003). However, despite several experimental and neuropathological correlations, it re-

\footnotetext{
Received April 6, 2005; revised Nov. 30, 2005; accepted Dec. 6, 2005.

This work was supported by Deutsche Forschungsgemeinschaft Grant SFB400/A8 to M.T.H. and T.K. and by an International Brain Research Organization grant to M.R.

Correspondence should be addressed to Dr. Michael T. Heneka, Department of Neurology, University of Münster, Albert Schweitzer Strasse 33, 48149 Münster, Germany. E-mail: heneka@uni-muenster.de.

DOI:10.1523/JNEUROSCI.4236-05.2006

Copyright $\odot 2006$ Society for Neuroscience $\quad$ 0270-6474/06/261343-12\$15.00/0
}

mains unclear whether and how LC cell death influences the pathogenesis of AD.

Physiologically, LC-derived NA plays an important role in selective attention, general arousal, and stress reactions (Foote et al., 1983). Although selective lesioning of noradrenergic neurons with $N$-(2-chloroethyl)- $N$-ethyl-bromo-benzylamine (dsp4) does not affect working (Ohno et al., 1997) or spatial memory (Sirvio et al., 1994; Lapiz et al., 2001), it exacerbates memory deficits induced by blocking muscarinic acetylcholine receptors (Ohno et al., 1997). A recent study showed a facilitator role of NA in the retrieval of spatial and contextual memories within a limited time (Murchison et al., 2004). Two types of LC-derived axonal terminals have been described: conventional synaptic structures and varicosities. These varicosities are believed to release NA extrasynaptically, which allows for its diffusion into the microenvironment where it may act on surrounding neurons, glial cells, and blood vessels (Marien et al., 2004). Extrasynaptic NA is thought to execute additional functions apart from its role as classical neurotransmitter. NA blocks the expression of inflammation-induced proteins, including major histocompatibility complex class II (Frohman et al., 1988), tumor necrosis factor- $\alpha$ (Hu et al., 1991), interleukin-1 $\beta$ (IL-1 $\beta$ ) (Willis and Nisen, 1995), and inducible nitric oxide synthase (iNOS) in astrocytes and microglia (Feinstein et al., 2002). In vivo noradren- 
ergic depletion reinforces the increase of iNOS, IL- $1 \beta$, and cyclooxygenase 2 evoked by intracortical injection of $\mathrm{A} \beta$ (Heneka et al., 2002). Therefore, it has been proposed that NA serves as an endogenous anti-inflammatory agent.

Considerable evidence suggests that neuroinflammation is associated tightly with and contributes to AD pathology (Akiyama et al., 2000). LC degeneration and reduced NA-mediated antiinflammatory protection could exacerbate inflammatory events and thereby add to AD pathogenesis. However, NA depletion may well affect $A \beta$ deposition directly, because it occurs as an early part of the $\mathrm{AD}$ disease process. We have analyzed whether NA depletion by either mechanism might modify the downstream AD-like pathology. Using amyloid-containing amyloid precursor protein 23 (APP23) transgenic mice, we demonstrate that a loss of LC neurons increases glial inflammation, amyloid plaque load, and neuronal cell death in LC projection areas, collectively causing impaired neuronal metabolism, reduced neuronal integrity, and cognitive deficits. Our results provide evidence for a link among LC degeneration, the resulting neuroinflammation, and classical AD pathology.

\section{Materials and Methods}

Animals. Female APP23 transgenic mice (Sturchler-Pierrat et al., 1997) were used, which express the human APP751 isoform with the Swedish double mutation (K670N-M671L) under control of a murine Thy1.2 expression cassette. The animals were hemizygous or littermate control mice and had been backcrossed with C57BL/6J mice for at least eight generations. Animals received food and water ad libitum except in the period of the eight arm radial maze test. During this time they received only $85 \%$ of the food quantity they consumed when having free access to food. At the time the animals were killed, they were anesthetized and perfused transcardially with heparinized sodium chloride $(0.9 \%)$, the brains were removed, and regions were dissected from one hemisphere with the use of the mouse brain atlas coordinates. Dissected sections were snap frozen in liquid nitrogen and stored at $-80^{\circ} \mathrm{C}$ until analysis. The remaining hemisphere was fixed in $4 \%$ paraformaldehyde, followed by paraffin embedding, or underwent cryofixation under tissue protection with tissue-freezing medium (Leica Instruments, Nussloch, Germany) according to standard protocols, before being sectioned for immunohistochemistry. Animal care and handling were performed according to the Declaration of Helsinki and approved by local ethical committees (approval number 50.203.2BN 33,34/00).

Lesions of the noradrenergic system. Lesions of the noradrenergic system need to be selective, leaving other aminergic systems intact; dsp4 is a site-directed alkylating neurotoxin with an affinity for the neuronal uptake transporter (Dudley et al., 1990). It accumulates within nerve terminals, depletes NA by affecting its transport, and can be administered intraperitoneally. In rodents dsp4 produces a terminal retrograde degeneration that is dose-dependent, requiring at least $40-50 \mathrm{mg} / \mathrm{kg}$ to deplete $>80 \%$ of NA in the cerebral cortex (Marien et al., 2004). It is important to note that dsp4 affects the majority of noradrenergic neurons originating from the LC, but not the small percentage of fibers ascending from cell groups A1 and A2 (Marien et al., 2004). Because LC neurons primarily project to the cortex and hippocampus, whereas noradrenergic neurons of the $\mathrm{A} 1$ and $\mathrm{A} 2$ region serve the paraventricular thalamus (Foote et al., 1983; Fritschy and Grzanna, 1989), hypothalamus, and preoptic areas, dsp4 treatment closely mimics AD-like LC degeneration. The paraventricular thalamus, which in the mouse brain ranges from -0.22 to -2.3 (rostral to caudal extension in relation to bregma) and from 0.0 to 0.35 (medial to lateral extension) (Paxinos and Franklin, 2001), is used as an important control region in dsp4-treated animals because it remains unaffected.

Four groups of animals were included in the study: nontransgenic littermate controls (wt) and APP23 transgenic mice (tg) with either saline (con) or dsp4 (dsp4) treatment at 10 months of age. Dsp4 or $0.9 \%$ saline was injected intraperitoneally twice, at days 1 and 7 , at a concentration of $50 \mathrm{mg} / \mathrm{kg}$. Animals were kept in groups of three to five. At $30 \mathrm{~min}$ before dsp4 the animals received fluoxetine $(10 \mathrm{mg} / \mathrm{kg})$ to protect serotonergic fibers, thereby increasing the selectivity of dsp4 for noradrenergic neurons. A description of the general, in particular inflammatory, acute effects of dsp4 application in the animals has been published previously (Heneka et al., 2002).

Determination of NA concentration. NA concentration was analyzed in brain lysates from frontal cortex and hippocampus with the use of HPLC and electrochemical detection (HPLC-ECD) according to standard protocols (Harro et al., 1999). In brief, after decapitation the brains were removed quickly, and brain regions were dissected on wet ice. Samples were weighted and homogenized in $0.2 \mathrm{ml}$ (hippocampus) or $0.3 \mathrm{ml}$ (frontal cortex) of $0.1 \mathrm{M}$ perchloric acid (0.01\% EDTA), using 3,4 dihydroxybenzylamine (DHBA; $25 \mu \mathrm{g} / \mathrm{ml}$ ) as an internal standard (EDTA/ DHBA; Sigma, Taufenkirchen, Germany). Homogenates were centrifuged at $4^{\circ} \mathrm{C}$ at $16,000 \times g$ for $10 \mathrm{~min}$. A $20 \mu \mathrm{l}$ volume of the resulting supernatant was injected onto a reverse phase column $(4.0 \times 100 \mathrm{~mm}$; Agilent, Palo Alto, CA) coupled to an electrochemical detector (Biometra EP30, Niedersachsen, Germany). The mobile phase consisted of $0.1 \mathrm{~mm}$ EDTA, $0.1 \mathrm{M}$ sodium phosphate monobasic monohydrate, $2 \mathrm{M}$ octanesulfonic acid, and $4 \%$ acetonitrile, $\mathrm{pH} 3.1$. The flow rate was $1 \mathrm{ml} / \mathrm{min}$. NA quantification was performed by comparison of peak heights of samples with known quantities of NA standards and DHBA. Data were collected and analyzed by using HP ChemStation software (Hewlett Packard, Palo Alto, CA) and expressed as nanograms/milligram wet weight.

Immunohistochemistry. Serial sagittal sections were cut $(7 \mu \mathrm{m})$ from cryofixed tissue (Leica microtome RM2155) and mounted (Histobond adhesion slides; Leica, Marienfeld, Germany). Retrieval of antigen sites, blocking of endogenous peroxidase activity, and blocking of nonspecific binding sites were performed according to standard protocols (Heneka et al., 2002). For immunostaining the sections were incubated overnight at $4^{\circ} \mathrm{C}$ with the following primary antibodies: mouse monoclonal antibody $(\mathrm{mAb})$ against glial fibrillary acidic protein (GFAP), number MAB360 (1:800; Chemicon, Hofheim, Germany); rabbit polyclonal antibody (pAb) against $\mathrm{A} \beta_{1-42}$, number 44-344 (1:40; BioSource, Camarillo, CA); $\mathrm{mAb}$ raised against mouse tyrosine hydroxylase (TH) number 22941 (1:1000; DiaSorin, Stillwater, MN); mouse mAb anti-nitrotyrosine (3NT) number 05-233 (1:40; 3-NT/A $\beta_{1-42}$; Biomol, Hamburg, Germany); mouse mAb number MAB377 against neuronal nuclei (NeuN; 1:500; Chemicon). Immunohistochemical localization was performed by using the avidin-biotin peroxidase complex method (ABC kit; Vector Laboratories, Burlingame, CA) with 3,3'-diaminobenzidine tetrahydrochloride as a chromogen.

All other single or double immunostaining was performed on cryofixed sections cut $(6 \mu \mathrm{m})$ and mounted as described above. Sections were dried at room temperature for $1 \mathrm{~h}$ and then fixed in $4 \%$ paraformaldehyde or methanol for $15 \mathrm{~min}$ at room temperature. After a washing with PBS the double staining was performed by simultaneously adding both first antibodies, followed by overnight incubation at $4^{\circ} \mathrm{C}$. In addition to the above described antibodies, the following antibodies or concentrations were used: rabbit pAb anti-nitrotyrosine number AB5411 (1:100; 3-NT/NeuN; Chemicon); rat mAb number MCA711 against murine CD11b (1:250; Serotec Düsseldorf, Germany); rabbit pAb GFAP, number Z334 against GFAP (1:800; DAKO, Hamburg, Germany). The goat secondary antibodies (fluorescein dichlorotriazinylaminofluoresceinconjugated anti-rabbit 1:150, Texas Red-conjugated anti-mouse 1:80, Texas Red-conjugated anti-rat 1:80; Jackson ImmunoResearch, West Grove, PA) were applied sequentially after being washed in PBS.

Negative controls included nonspecific IgG instead of primary antibodies, preabsorption with respective cognate peptides (150-200 $\mu \mathrm{g}$ of peptide/ml of antibody working solution), omission of the secondary antibody, and absence of immunoreactivity in nontransgenic controls of the respective age.

Confocal laser-scanning microscopy. Double-labeled specimens were analyzed with a confocal laser-scanning microscope (Multiprobe 2001; Molecular Probes, Eugene, OR) equipped with an Ar/Kr laser with balanced emission at 488, 568, and $647 \mathrm{~nm}$. To achieve an optimal signalto-noise ratio for each fluorophore, we used sequential scanning with 568 and $488 \mathrm{~nm}$. Then the digitized images were processed with ImageSpace 3.10 software (Molecular Probes) on a Silicon Graphics (Mountain View, 
CA) power series 310GTX work station. Original section series were subjected to Gaussian filtration to reduce noise and enhance weakly but specifically labeled parts. Original and filtered sections were projected on one plane, using a maximum intensity algorithm and in some cases using depth-coding and surface-rendering algorithms.

Acid fuchsin histology. Acid fuchsin staining was performed as previously described. In brief, sections were washed in deionized water three times for $5 \mathrm{~min}$ each, dehydrated, and mounted on slides according to standard protocols. Thereafter, the sections were stained with $1 \%$ acid fuchsin (F8129; Sigma) to detect severely damaged neuronal cells (Kiernan et al., 1998).

Thioflavine S staining. Thioflavine S staining consisted of incubating sections in $0.015 \%$ aqueous thioflavine $S$ for $10 \mathrm{~min}$, followed by differentiation in 50\% ethanol, rinsing in water, air draining, and clarification into xylene. Thereafter, the slides were covered and evaluated under fluorescent lighting with the use of UV filtration and a standard microscope (Leica DM IRB).

Quantification of immunohistochemistry. For quantitative image analysis of hippocampal and cortical immunostaining, serial sagittal sections of one hemisphere taken from the lateral $(+0.5$ to +2.25$)$ were examined. CD11b, GFAP, NeuN, acid fuchsin, 3-NT, and $\mathrm{A} \beta_{1-42}$ immunostainings were evaluated on brain sagittal sections of 20 animals from each group. For each animal the antigens were detected in 10 (CD11b, GFAP, 3-NT, NeuN, acid fuchsin) or $20\left(\mathrm{~A} \beta_{1-42}\right)$ parallel sections having a defined distance of $70 \mu \mathrm{m}$ and showing both the hippocampus and cortex. In each section the hippocampus and the frontal cortex were defined and evaluated according to histomorphological hallmarks and comparison to a mouse brain atlas (Paxinos and Franklin, 2001). As parameters, total stained area and integrated staining density (sum of all individual optical densities of each pixel in the area being measured) were determined for each section and given as a stained area in micrometers squared/millimeters squared (CD11b, GFAP) or a percentage of stained area per region $\left(\mathrm{A} \beta_{1-42}\right)$. For LC quantification the serial coronal midbrain sections were cut along the caudorostral extent as previously described (Bezin et al., 1994). Then noradrenergic LC neurons were visualized by TH staining and subsequently were counted. For NeuN and acid fuchsin the plaque areas (confirmed by $\mathrm{A} \beta_{1-42}$ staining of some adjacent sections) were excluded, and the number of stained cells was counted and given as immunopositive neurons per millimeter squared. Because the high density of NeuN-positive neurons in the dentate gyrus did not allow for reliable counting, two subregions, the CA1 field and the subiculum, were chosen for quantitative analysis. All images were acquired by using a standard light and immunofluorescence microscope (Eclipse E-800; Nikon, Tokyo, Japan) connected to a digital camera (Sony model DXC-9100P, Köln, Germany) and to a PC system with LUCIA imaging software (LUCIA 32G, version 4.11; Laboratory Imaging, Düsseldorf, Germany). For each animal the average values from all sections were determined. These data were analyzed by ANOVA with Tukey's posttests, using SYSTAT software (Systat, Evanston, IL). To determine the distance of acid fuchsin-labeled neurons from plaque center, we digitized images and the plaque center (as indicated by a plus sign) surrounded by several concentric rings with defined and calibrated diameters. The number of neurons within each ring was plotted versus the distance of the ring (middle) from the plaque center. In the areas of high plaque density double counting was excluded by associating each acid fuchsin-labeled neuron with one plaque center only.

Western blotting. Mouse brains were homogenized in RIPA buffer $(1 \%$ Triton X-100, 1\% sodium deoxycholate, 0.1\% SDS, $150 \mathrm{~mm} \mathrm{NaCl}, 50 \mathrm{~mm}$ Tris- $\mathrm{HCl}, \mathrm{pH}$ 7.2), using an Ultraturrax T25 (Janke \& Kunkel, Staufen, Germany). The $100 \mu \mathrm{g}$ protein samples were separated in 10\% SDS gels, transferred onto Immobilon-P polyvinylidene difluoride membranes, and blotted with a polyclonal iNOS antibody at 1:500 dilution (Cayman Chemicals, Ann Arbor, MI). The specificity for the iNOS antibody that was used has been confirmed by positive controls containing iNOS protein (data not shown). Blots were developed by using ECL (Amersham Biosciences, Freiburg, Germany) and quantified by densitometry.

Determination of $A \beta$. A $\beta$ was immunoprecipitated from $100 \mu \mathrm{g}$ of protein from different brain areas with the use of antibodies 4G8 (Signet, Dedham, MA) or 2964 and protein A beads (Amersham Biosciences), sepa- rated on 4-12\% NuPAGE gels (Invitrogen, Karlsruhe, Germany) or $\mathrm{N}, \mathrm{N}$ bis-(2-hydroxyethyl)-glycine/bis-Tris/Tris/sulfate SDS/urea-PAGE to discriminate between $\mathrm{A} \beta_{1-40}$ and $\mathrm{A} \beta_{1-42}$ isoforms. $\mathrm{A} \beta$ was detected by immunoblotting with antibody $6 \mathrm{E} 10$ (Signet) and quantified by densitometric scanning.

Anatomical quantification of vesicular acetylcholine transporter content in cortical and hippocampal regions. The degree of cholinergic innervation was assessed by using the vesicular acetylcholine transporter (VAChT) as a marker for cholinergic boutons, as previously described (Debeir et al., 1999). After saturation of nonspecific antibody-binding sites by incubation of the nonperfused tissue sections for $30 \mathrm{~min}$ in PBS solution (50 $\mathrm{mm}, \mathrm{pH} 7.4$ ) containing $1 \%$ bovine serum albumin (BSA), the sections were incubated at $4^{\circ} \mathrm{C}$ in the presence of the primary VAChT antibody from rabbit (1:10,000; a gift from Dr. R. H. Edwards, University of California San Francisco School of Medicine, San Francisco, CA) for $12 \mathrm{~h}$, washed three times with PBS/BSA for $10 \mathrm{~min}$, and transferred to a solution of PBS containing ${ }^{35}$ S-labeled anti-rabbit IgG (specific activity, 227 $\mathrm{Ci} / \mathrm{mmol}$; 1:100 dilution; initial concentration, $20 \mu \mathrm{g} / \mathrm{ml}$; Amersham Biosciences) for $2 \mathrm{~h}$. Finally, the sections were rinsed in PBS three times for $10 \mathrm{~min}$, dried rapidly under a stream of air, and apposed to Kodak BioMax (Eastman Kodak, Rochester, NY) in Kodak x-ray film cassettes at room temperature. Films were developed 72 h later with Kodak D-19 developer. To determine whether the immunoautoradiography procedure affords a linear relationship between autoradiographic detection and the amount of radioactive secondary antibody, we immobilized from $1: 10$ to $1: 50,000$ dilutions of ${ }^{35}$ S-labeled anti-rabbit IgG onto nitrocellulose.

Quantification of VAChT autoradiograms. In the cerebral cortex and hippocampus the area of VAChT radio immunolabeling was estimated on autoradiograms by densitometric analysis of $\mathrm{x}$-ray films (Explora Nova, La Rochelle, France). Measurements of the optical density (OD) of the cortex and hippocampus were done by following the landmarks established by Paxinos and Franklin (2001): frontal cortex, bregma 0.26, next to the cingulum; parietal cortex, bregma $0.26,0.6 \mathrm{~mm}$ dorsal to the rhinal fissure; hippocampus, bregma $-2.30 \mathrm{~mm}$, stratum radiatum of the CAl region. Autoradiographic $\left[{ }^{14} \mathrm{C}\right]$ microscales $(1.15-32.7 \mathrm{kBq} / \mathrm{g}$; 31-883 nCi/g; Amersham Biosciences) were used as a calibration standard. Results are shown as the mean \pm SEM. To compare the VAChT immunoradiography (VAChT-IR) density among different groups of mice, we used one-way ANOVA, followed by a Tukey's test. The level of significance was set as $p<0.05$.

Behavioral studies. Mice were housed for at least 2 weeks in a reversed light/dark cycle (lights off at 9:00 A.M. and on at 8:00 P.M.) before the behavioral studies, which were performed during the active phase of the animals. Tests were conducted at least 1 week apart.

Eight arm radial maze. Learning and memory testing for each mouse were conducted in an eight arm maze constructed of wood and elevated $50 \mathrm{~cm}$ from the floor. Each of the arms was $60 \mathrm{~cm}$ long and $6 \mathrm{~cm}$ wide and extended from an octagonal central platform $10 \mathrm{~cm}$ across. Food cups 1 $\mathrm{cm}$ deep were placed $2 \mathrm{~cm}$ from the end of each arm. The testing room contained several visual cues outside of the maze and was lit dimly while sessions were in progress. Initially, the mice were trained for $3 \mathrm{~d}$. During each training session the mouse was placed on the center platform and allowed to move freely in the maze to obtain food pellets, which were presented in all eight arms, for a period of $10 \mathrm{~min}$. From day 4 on the mice were tested one session per day for a total of $14 \mathrm{~d}$. During the test sessions four randomly selected arms were baited with one pellet of food each; the baited arms were kept unchanged throughout the experiment. The mouse was allowed to move freely in the maze until it collected the four pellets of food or until 10 min passed, whichever occurred first. Three parameters were evaluated: (1) reentry into baited arms that had been visited during the session (working memory errors), (2) entries into unbaited arms (reference memory errors), and (3) total arm entries needed for the collection of all of the pellets in the maze. The task was considered learned when the working memory error was zero and the average reference memory error was one or less than one in three successive sessions (Olton, 1987). The ratio of mice reaching the criterion level was determined and compared between groups with the use of Fisher's exact test. Seven of 10 saline-treated and five of nine dsp4-treated wild- 

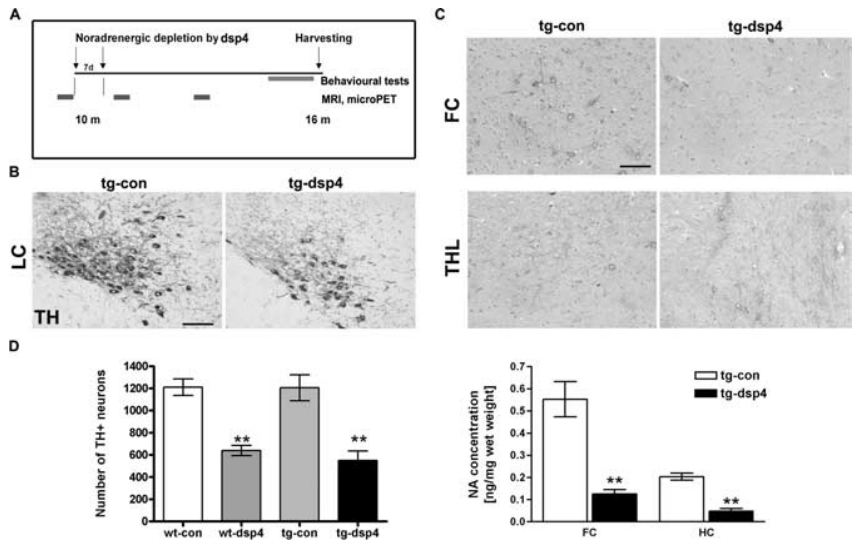

Figure 1. LC degeneration and NA depletion. A, Experimental time course. The 10-monthold APP23 transgenic mice and age-matched littermate controls received two intraperitoneal injections of dsp 4 within 1 week to induce NA depletion and LC degeneration or were injected with PBS as a control. A subset of animals underwent recordings for micro-PET studies before (baseline), 4 , and 12 weeks after dsp4 treatment. At the end of a 6 month period the animals were subjected to behavioral tests, and the brains subsequently were removed for analysis. $\boldsymbol{B}$, TH immunostaining of the midbrain showed that control injections did not affect $\mathrm{LC}$ neurons (tg-con), but dsp4 treatment caused noradrenergic cell death (tg-dsp4). C, Loss of noradrenergic axon terminals detected by NA immunohistochemistry was absent in controls (tg-con) but observed in the frontal cortex of the dsp4 group. The paraventricular thalamus (THL) remained unaffected by dsp4. $D$, A stereological quantification of the number of TH-positive neurons in the different experimental groups is given on the left, which confirms the effect of dsp4 treatment. A loss of NA as demonstrated by a quantification of the NA concentration in the frontal cortex $(\mathrm{FC})$ and hippocampus $(\mathrm{HC})$ is shown. NA concentrations were determined by HPLC-ECD. Note the $>70 \%$ reduction (mean $\pm \mathrm{SEM} ; n=10$ animals per group; ANOVA, followed by a Tukey's test; ${ }^{* *} p<0.01$ ). Scale bars: $\boldsymbol{B}, 100 \mu \mathrm{m} ; \boldsymbol{C}, 50 \mu \mathrm{m}$.
Partner recognition test. This test was conducted in an open field arena $(44 \times 44 \mathrm{~cm})$ in a dimly lit sound-isolated environment. The floor of the arena was covered with sawdust saturated with the odor of mice. Initially, the animals were habituated to the arena for 5 min daily for $4 \mathrm{~d}$. On day 5 the animals were put back into the familiar arena in which a young ( 3 weeks old) female DBA/2J mouse was present. The activity of mice was videotaped for $5 \mathrm{~min}$. Then $1 \mathrm{~h}$ later the test was repeated with the same partners and in the same arena. Time spent with social interactions in the first and second trials was registered by an observer blind to phenotype or treatment and evaluated with The Observer software (Noldus). A reduction in social interaction time in the second trial with the use of the Student's paired $t$ test indicated recognition. The partner recognition test was repeated 1 week later in the same way as described above, but a novel partner instead of a familiar partner was presented in the second session.

Open field exploration. Mice were placed into the center of a dimly lit $(20-30$ lux $)$ chamber of the open field apparatus $(44 \times 44 \times 30 \mathrm{~cm})$. Movements of the animals were tracked by an automatic monitoring system (TSE, Bruchsal, Germany) for $15 \mathrm{~min}$. Horizontal (distance traveled) and vertical activity (number of rears) was evaluated. The experiment was repeated on 3 consecutive days. Groups were compared by two-way ANOVA (within factor, repetition; between factor, group), followed by the SNK test.

Micro-positron emission tomography and magnetic resonance imaging. Multi-tracer micro-positron emission tomography (micro-PET) imaging was performed as described previously (Schubert et al., 2004) in APP23 mice $(n=20)$ and wild-type (wt) mice $(n=12)$ at the age of 10 months (baseline). Three sets of animals were studied. In the first set of animals nontreated APP23 $(n=6)$ and wt mice $(n=6)$ were investigated at baseline and 3 months later to determine the differences between each group of animals and intra-individual differences because of aging. In the second set, dsp4 $(n=3$ each) and saline-treated $(n=3$ each) APP2 3 and wt mice were analyzed 4 weeks later to assess additional effects of LC type mice reached the criterion. In contrast, none of the NA-depleted transgenics and only one of the saline-treated transgenic mice was able to learn the task ( $p=0.01$ and $p=0.02$, respectively, compared with control). Performance of groups was compared by using twoway ANOVA (between factor, groups; within factor, trials), followed by the Student's-Newman-Keuls (SNK) test.

Object recognition test. This test was conducted in an open field arena $(44 \times 44 \mathrm{~cm})$ in a dimly lit sound-isolated environment. The floor of the arena was covered with sawdust saturated with the odor of mice. Initially, the animals were habituated to the environment for 5 min daily for $4 \mathrm{~d}$. On day 5 two objects were placed into the arena (identical plastic balls, 2 $\mathrm{cm}$ in diameter; objects $\mathrm{A}$ ), and the animals were allowed to explore the area and the objects for $5 \mathrm{~min}$. Then $1 \mathrm{~h}$ later the animals were put back into the same box in which one familiar and one novel object [similar size ball, different shape (oval) and color; object B] were placed. The behavior of mice was videotaped; time spent with inspections of each object (TA for object A and TB for object B) was determined by an observer blind to phenotype or treatment who used The Observer software (Noldus, Wageningen, The Netherlands). The preference ratio, $(\mathrm{TA} \times 100) /(\mathrm{TA}+\mathrm{TB})$, was calculated. We considered that the animals recognized the previously presented object when the preference ratio decreased significantly in the second presentation. Data were analyzed by Student's paired $t$ test.
A
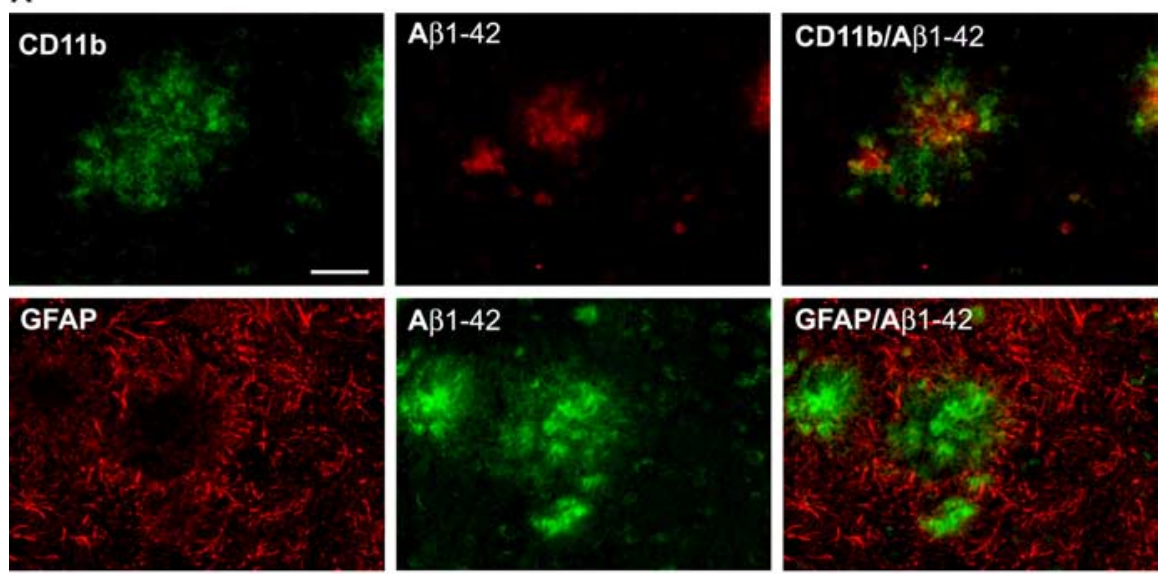

B
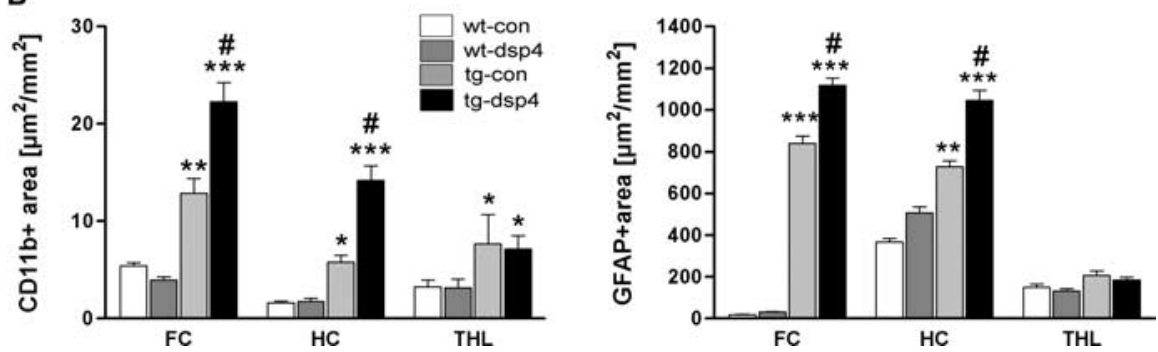

Figure 2. Noradrenergic depletion increases glial activation. $\boldsymbol{A}$, Confocal immunostaining of microglia (CD11b) and astrocytes (GFAP) showed the close proximity of both cell types to $A \beta_{1-42}$-positive plaques in APP23 mice. Scale bar, $50 \mu \mathrm{m}$. $B$, Quantitative analysis of the total area stained by CD11b or GFAP (given as $\mu \mathrm{m}^{2} / \mathrm{mm}^{2}$ ) in the frontal cortex (FC), hippocampus (HC), and paraventricular thalamus (THL) of wild-type controls (wt-con), wild-type dsp4-treated animals (wt-dsp4), APP23 controls (tgcon), and dsp4-treated APP23 mice (tg-dsp4) (mean \pm SEM; $n=20$ animals per group; ANOVA, followed by a Tukey's test). For $\operatorname{tg}$ versus con, ${ }^{*} p<0.05,{ }^{* *} p<0.01$, and ${ }^{* * *} p<0.001$; for tg-con versus tg-dsp4, ${ }^{\#} p<0.01$. 
A
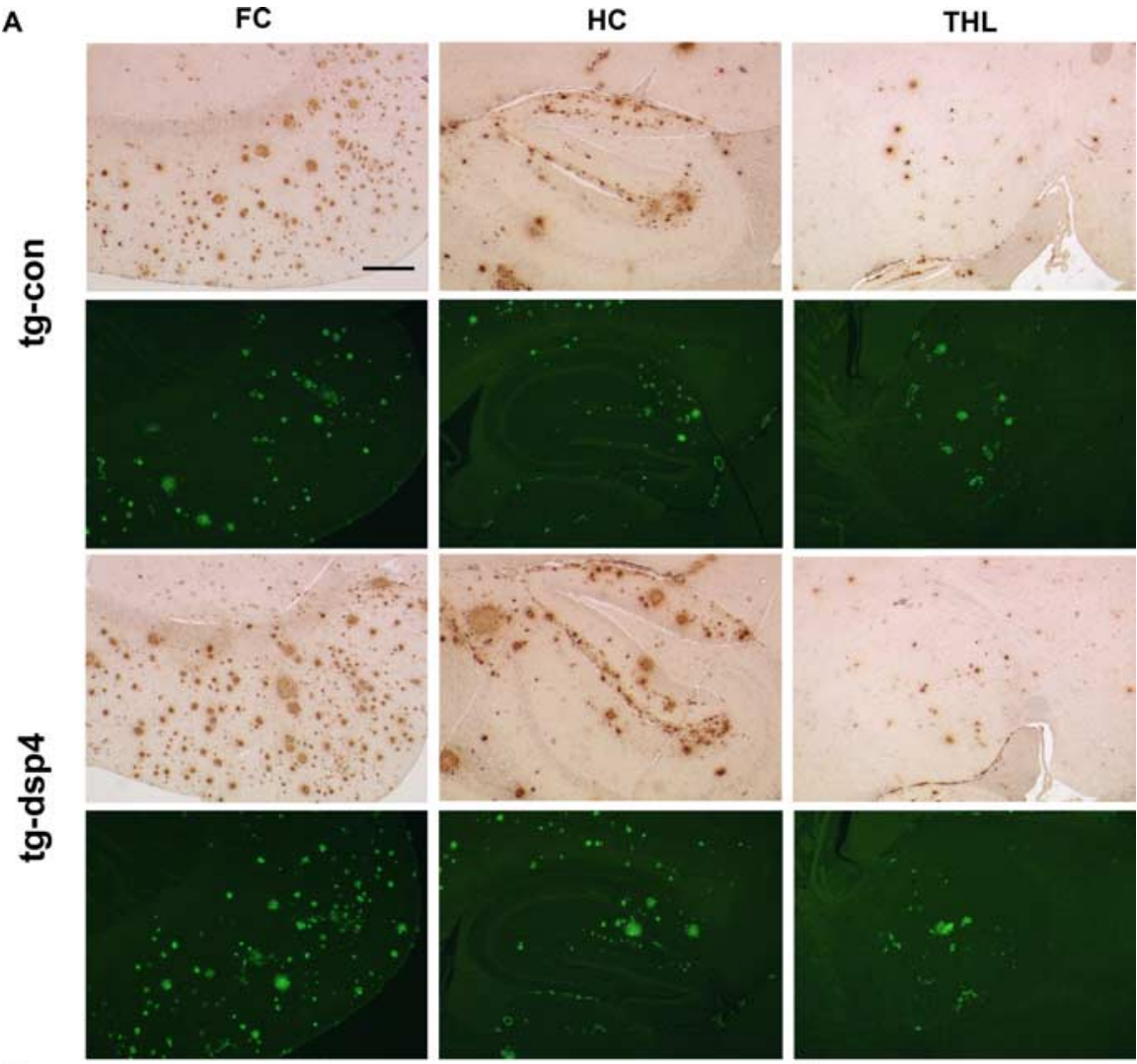

B
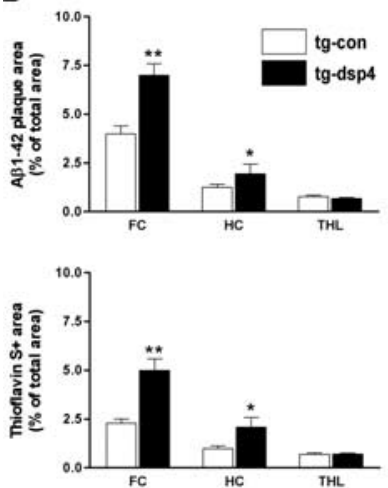
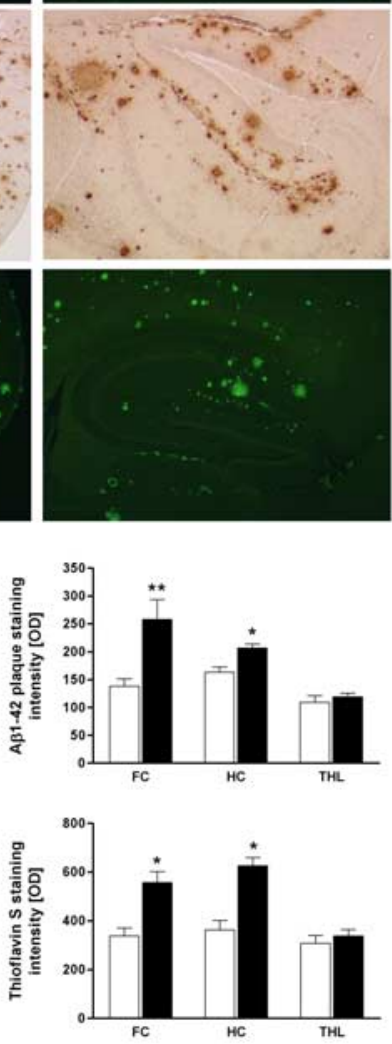

dsp4
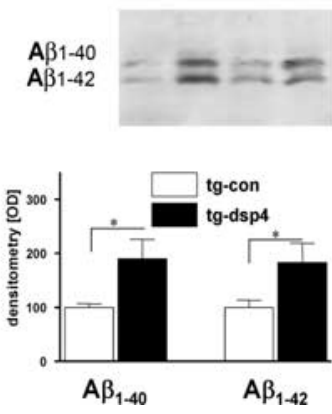

Figure 3. Increased deposition of amyloid peptides $A \beta_{1-42}$ and $A \beta_{1-40}$ in NA-depleted APP23 mice. $A$, Sections of the frontal cortex (FC), hippocampus (HC), and paraventricular thalamus (THL) from saline-injected (tg-con) and NA-depleted APP23 (tgdsp4) mice were stained with antibodies directed against $A \beta_{1-42}$ or with thioflavine $S$. Labeling of both $L C$ projection areas (FC, $\mathrm{HC}$ ) revealed a marked increase of amyloid deposits. In contrast, no differences of $A \beta$ deposition were observed in the THL. Scale bar, $250 \mu \mathrm{m} . B$, Quantification of plaque load ( $A \beta_{1-42}$ or thioflavine $S$-stained plaque area as a percentage of total region) and plaque staining intensity revealed statistically significant increases in amyloid deposition in response to $\mathrm{LC}$ degeneration in the $\mathrm{FC}$ and HC, but not within the THL (mean \pm SEM; $n=20$ animals per group; ANOVA, followed by a Tukey's test; ${ }^{*} p<0.05,{ }^{* *} p<$ 0.01). C, Western blot detection and subsequent densitometric analysis of $A \beta_{1-40}$ and $A \beta_{1-42}$ in lysates of the $H C$, a $L$ C projection area, confirmed the immunohistochemical results (mean \pm SEM; $n=8$; ANOVA, followed by a Tukey's test; ${ }^{*} p<0.05$ ).

depletion. In the third set, APP23 mice with $(n=4)$ and without $(n=4)$ dsp4 treatment were investigated 4 and 12 weeks after dsp4 application. Micro-PET was performed after injection of $2-\left[{ }^{18} \mathrm{~F}\right]$ fluoro-2-deoxy-Dglucose $\left(\left[{ }^{18} \mathrm{~F}\right] \mathrm{FDG}\right)$ for the assessment of the cerebral metabolic rate of glucose (CMRGlc), of [ $\left.{ }^{11} \mathrm{C}\right]$ flumazenil $\left(\left[{ }^{11} \mathrm{C}\right] \mathrm{FMZ}\right)$ as surrogate marker for neuronal integrity, and of $\left[{ }^{11} \mathrm{C}\right] N$-methyl-4-piperidyl-acetate $\left(\left[{ }^{11} \mathrm{C}\right] \mathrm{MP} 4 \mathrm{~A}\right)$ for the evaluation of acetylcholine esterase activity. Tracer injections were performed under halothane anesthesia by intravenous application of $\left[{ }^{18} \mathrm{~F}\right] \mathrm{FDG}(7.6 \pm 1.4 \mathrm{MBq}),\left[{ }^{11} \mathrm{C}\right] \mathrm{FMZ}(8.4 \pm 4.1 \mathrm{MBq})$, and $\left[{ }^{11} \mathrm{C}\right] \mathrm{MP} 4 \mathrm{~A}(6.0 \pm 2.1 \mathrm{MBq})$, respectively. During tracer uptake the mice were conscious. Subsequent micro-PET imaging was performed under ketamine/xylazine anesthesia. Emission scans were obtained 30-60 min after tracer injection. For quantification of brain glucose metabolism, $\left[{ }^{11} \mathrm{C}\right] \mathrm{FMZ}$ binding, and $\left[{ }^{11} \mathrm{C}\right] \mathrm{MP} 4 \mathrm{~A}$ uptake, a set of corresponding reference standards of different radioactivity concentrations was placed within the field of view of the microPET scanner. Maximum a posteriori (MAP) reconstruction was performed without scatter and attenuation correction. Data were evaluated by a region of interest (ROI) analysis of transaxial micro-PET images through cortex and cerebellum to determine radioactivity concentrations. ROIs were placed into the cortex/ hippocampal region of both sides and the cerebellum. Injected dose per gram and cortex-tocerebellum ratios were calculated. Data were decay-corrected and divided by the total injected dose (ID) to represent the percentage ID dose per gram (\% ID/g) and were expressed as the fold difference from background (cerebellum) activity (cortex-to-cerebellum ratio). To ensure proper ROI placement, we coregistered micro-PET images with high-resolution magnetic resonance brain images (7 tesla) as described previously (Schubert et al., 2004). To compare differences in relative radiotracer accumulation between APP23 and wt mice, we performed Student's $t$ test. To assess intraindividual differences between baseline and follow-up micro-PET measurements, we performed Student's paired $t$ test. For statistical analysis we used Microsoft Office Excel 2003 (Microsoft, Redmond, WA) and SigmaStat 2003 (SPSS, Chicago, IL).

\section{Results}

\section{LC degeneration and} noradrenergic depletion

Depletion of the noradrenergic system was induced in amyloid plaque-containing 10 month-old APP23 mice as well as nontransgenic littermates (Fig. $1 A$, experimental outline). The amyloid load of APP23 mice is still relatively low at this time point, as expected for an early stage in $\mathrm{AD}$ pathogenesis. Animals received two intraperitoneal injections of either saline or dsp4, a toxin specific for noradrenergic LC neurons, which under suitable conditions leaves other brainstem nuclei unaffected (Heneka et al., 2002; Marien et al., 2004) (see also Materials and Methods). The reduction of noradrenergic LC neurons has been shown to occur rapidly (Harro et al., 1999; Heneka et al., 2002; Marien et al., 2004). To avoid strong acute reactions but to investigate long-term and potentially indirect effects of LC degeneration, we performed histological analyses 6 months later at an intermediate stage of amyloid deposition (amyloid increases $\sim 10 \times$ from 10 to 16 months and again $\sim 10 \times$ from 16 to 24 months).

At 16 months TH immunostaining revealed a $50-60 \%$ loss of LC neurons in response to dsp4 treatment (Fig. $1 B, D$ ), as previously described (Heneka et al., 2002). This decrease corresponds to the degree of neuronal LC degeneration observed in $\mathrm{AD}$ [sum- 
marized in the study by Zarow et al. (2003)]. The neuronal loss was similar in wild-type (wt-dsp4) and APP23 transgenic mice (tg-dsp4). Nonlesioned APP23 mice did not show LC degeneration compared with wild-type mice, confirming similar findings in animals older than 2 years ( $P$. Waldmeier and M. Staufenbiel, unpublished data). Dsp4 treatment did not affect the number of $\mathrm{TH}$-positive substantia nigra neurons (data not shown). Staining of frontal cortex sections with a NA antibody showed morphologically intact noradrenergic terminals in saline-treated wild-type or APP transgenic animals (Fig. $1 C$, wt-con, tg-con), whereas NA staining was almost absent in dsp4-treated APP23 transgenics (Fig. 1C, tg-dsp4) and wildtype (wt-dsp4) littermates (data not shown). The paraventricular thalamus, which remained unaffected (Fig. 1C), served as a reference because it receives NA innervation from cell groups outside of the LC (Foote et al., 1983; Fritschy and Grzanna, 1989; Marien et al., 2004). To determine the extent of the depletion, we quantified NA in brain lysates from cortex and hippocampus by using HPLC-ECD. A $>70 \%$ reduction of NA was found in dsp4-treated compared with control animals in both brain regions (Fig. 1D). These data confirm the dsp4-induced degeneration of $\mathrm{TH}$-positive noradrenergic LC neurons and the concomitant noradrenergic depletion of the projection areas. Although NA serves to identify noradrenergic neurons, it needs to be emphasized that these neurons secrete other molecules that are affected as well (see Discussion).

\section{Increase in microglial and astroglial activation at LC degeneration}

Confocal immunostaining of $\mathrm{CD11b}$ and GFAP revealed the close proximity of microglia and astrocytes to amyloid plaques in APP23 mice (Fig. 2 A). To assess whether long-term NA depletion affects brain inflammation, we quantified CD11b-positive microglia and GFAP-positive astrocytes in all animal groups. In wild-type controls only a few CD11b-positive cells were detectable. This remained unchanged after NA depletion (Fig. $2 \mathrm{~B}$, wtdsp4). Expression of the APP transgene caused a significant increase of CD11b staining (Fig. 2 B). In contrast to nontransgenic mice, NA depletion of APP23 transgenic mice additionally increased the CD11b-positive microglia cells in both the hippocampus and the frontal cortex (Fig. $2 \mathrm{~B}$ ). As expected, CD11b staining in the paraventricular thalamus was not altered by NA depletion. Similarly, determination of astroglia activation by GFAP staining showed almost no GFAP labeling in the cerebral cortex but a considerable number of GFAP-positive astrocytes within the hippocampus of nontransgenic mice (Fig. $2 \mathrm{~B}$ ). However, APP23 mice contained more GFAP-positive cells in both brain areas, but not in the paraventricular thalamus. Although astrocyte staining was not influenced by NA withdrawal in nontransgenic mice, APP transgenics showed a significant increase of GFAP-positive cells in the hippocampus and frontal cortex, but not in the paraventricular thalamus. Together, these data dem- onstrate an increased glial activation in NA-depleted APP transgenic mice, which is not observed in treated wild-type animals. Additionally, the transgene activated microglia, but not astrocytes, in the paraventricular thalamus, possibly indicating a relative resistance of astrocytes in this region to activation.

\section{LC degeneration increases amyloid plaque load}

We next tested whether a reduction of noradrenergic innervation affects the amyloid plaque pathology in APP23 mice. Via immunohistochemistry we quantified the area covered by $\mathrm{A} \beta_{1-42^{-}}$ positive plaques and the respective plaque-staining intensity in 20 animals per group by using 10 equally spaced sections for each mouse hemisphere. Brains from saline-treated APP23 mice (tgcon) contained numerous plaques in the hippocampus and the cerebral cortex and also showed amyloid deposits in the paraventricular thalamus (Fig. 3A). Quantitative analysis indicated that NA depletion (tg-dsp4) increased the plaque area as well as the staining intensity of $\mathrm{A} \beta_{1-42}$ (Fig. $3 A, B$ ) and $\mathrm{A} \beta_{1-40}$ (data not shown) in the frontal cortex and hippocampus, but not the paraventricular thalamus (Fig. $3 A, B$ ). Parallel sections also were stained for compact amyloid plaques by the use of thioflavine $S$ (Fig. 3A) and were quantified (Fig. 3B). In good agreement with the immunohistochemistry, amyloid deposits were found to be increased in the frontal cortex and hippocampus, but not in the paraventricular thalamus. These histological results were confirmed additionally by Western blot quantification of $\mathrm{A} \beta_{1-40}$ and $\mathrm{A} \beta_{1-42}$ in hippocampal lysates, which demonstrated a marked increase in NA-depleted transgenic mice (Fig. 3C). Together, these data suggest that the amyloid plaque load is increased selectively in regions depleted for NA. 
A
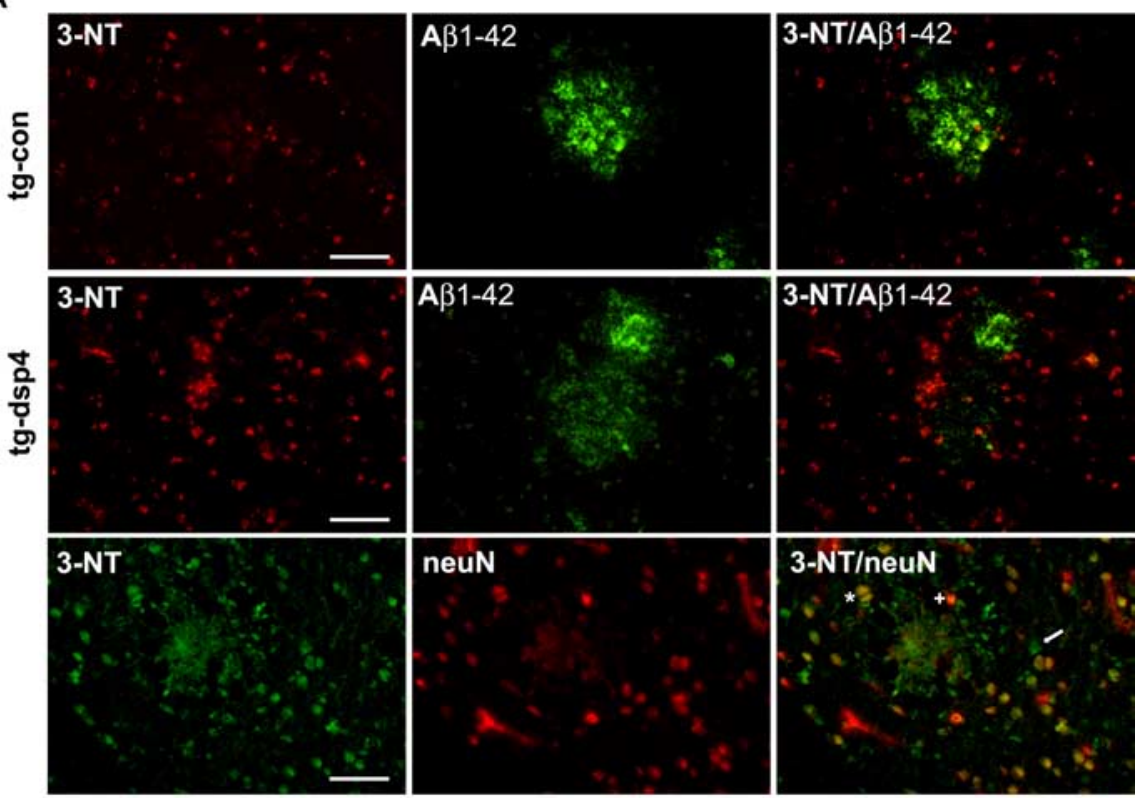

B

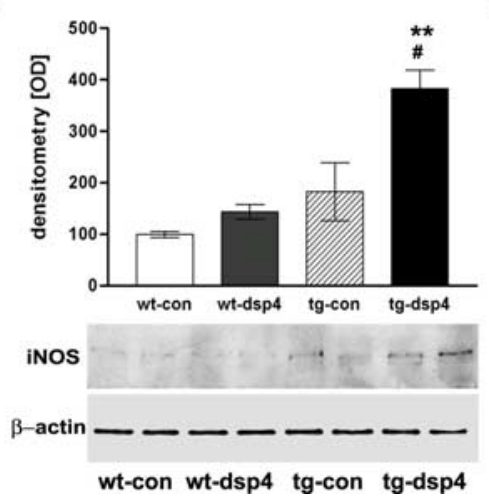

C

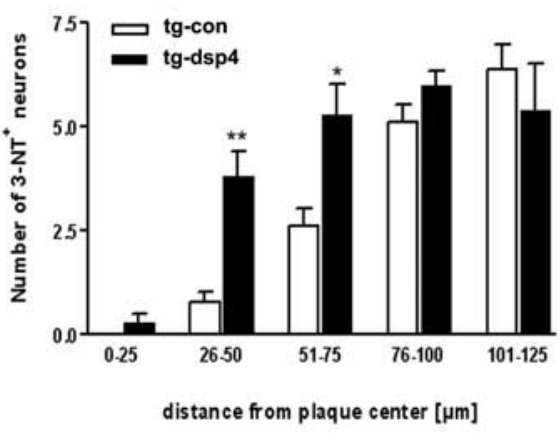

Figure 5. NA depletion elevates expression of iNOS and NO-dependent peroxynitrite formation. $\boldsymbol{A}$, Confocal immunostaining for 3-NT and $A \beta_{1-42}$ of control (tg-con) and dsp4-treated (tg-dsp4) APP23 mice illustrated an increased plaque-related 3-NT staining, indicating N0-dependent peroxynitrite formation at sites of amyloid deposition. Additional confocal analysis revealed that 3-NT strongly colocalized with the neuronal marker NeuN (white star); additionally, non-3-NT-labeled neurons (white plus sign) and non-NeuN-labeled cells mainly of microglial morphology (white arrow) were observed. Scale bars, $50 \mu \mathrm{m}$. B, Hippocampal lysates of wild-type controls (wt-con), wild-type dsp4-mice (wt-dsp4), tg-con, and tg-dsp4 were used for Western blot detection of iNOS. Densitometric analyses showed a strong increase of iNOS protein in dsp4-treated APP23 mice (mean \pm SEM; $n=8$ animals per group; ANOVA, followed by a Tukey's test). ${ }^{* *} p<0.01$ for wt-con versus tg-dsp4; $p<0.05$ for tg-con versus tg-dsp4. C, The number of NeuN/3-NT-colabeled neurons was counted in consecutive rings around the plaque centers, revealing a significant increase in NeuN/3-NT-labeled neurons from 26 to $75 \mu \mathrm{m}$ in dsp4-treated APP23 mice (mean \pm SEM; $n=6$; ANOVA, followed by a Tukey's test). ${ }^{*} p<0.05 ;{ }^{* *} p<0.01$.

\section{Augmented neuronal degeneration and cell loss}

A small loss of neurons can be observed in the hippocampus and in cortical regions of aged APP23 mice (Calhoun et al., 1998; Bondolfi et al., 2002). To assess whether NA depletion affects neuron number, we stained equally spaced sections for the neuronal marker NeuN (Fig. 4A); neurons were quantified in the frontal cortex, the subiculum, the hippocampal CA1 field, and the paraventricular thalamus (Fig. $4 B$ ). The area covered by plaques was not considered.

NA depletion did not affect the number of NeuN-positive neurons in wild-type mice. In contrast, NA-depleted APP23 mice showed a significantly reduced number of NeuN-stained neurons in the frontal cortex and the hippocampal region. Importantly, the number of NeuN-positive neurons in the paraven- tricular thalamus remained unaffected by NA depletion (Fig. 4B).

Degenerating neurons were visualized by using acid fuchsin, which stains basic proteins accumulating in nuclei and perikarya of degenerating, shrunken cells (Kiernan et al., 1998). Acid fuchsin staining (Fig. 4A) and its quantification (Fig. $4 B$ ) revealed only a few damaged cells in the frontal cortex of wild-type mice. Their number remained unchanged by NA depletion. Saline-injected APP23 mice, however, contained a significantly higher number of acid fuchsin-labeled cells in the frontal cortex. NA depletion resulted in a further and significant increase. Similar results were obtained for the hippocampus (data not shown). Again, no difference between NA-depleted and saline-treated APP23 was found for the paraventricular thalamus (data not shown). These findings additionally support the increased neuron loss in NA-depleted brain regions of APP23 mice.

The distance of acid fuchsin-labeled cells from amyloid plaque centers was evaluated in the frontal cortex and hippocampus to detect a possible relationship between damaged neurons and amyloid plaques. A peak of acid fuchsin-labeled neurons was located within a distance of $30-75 \mu \mathrm{m}$ from the plaque center only in NA-depleted APP23 mice. In addition, positive cells were spread evenly in a $40-$ $150 \mathrm{~mm}$ perimeter of amyloid plaque centers in dsp4 as well as saline-treated APP23 (Fig. $4 B$ ).

\section{Elevated levels of iNOS and} peroxynitrite in LC projection areas Previous data obtained after acute injection of fibrillar $A \beta_{1-42}$ into the rat frontal cortex indicated an increased expression of iNOS, which is potentiated by NA depletion (Heneka et al., 2002). Furthermore, iNOS induction and subsequent nitric oxide (NO) release can induce neuronal cell death. Therefore, we tested whether chronic deposition of $\mathrm{A} \beta$ with or without NA depletion would be associated similarly with increased iNOS expression and NO formation. In both NAdepleted and intact APP23 mice, iNOS-positive cells were found near amyloid plaques. As expected (Luth et al., 2001), a vast majority of these cells were identified as astrocytes by costaining with GFAP (data not shown). A minor number of the iNOS-positive cells in NA-depleted APP23 mice were NeuN-stained neurons (data not shown). Western blot quantification of iNOS in hippocampal lysates showed that wild-type controls expressed low amounts that did not change significantly by NA depletion. iNOS protein was slightly, but not significantly, elevated in salinetreated APP23 mice compared with nontransgenic controls. In contrast, iNOS expression was increased significantly in NAdepleted APP23 mice (Fig. 5B). 

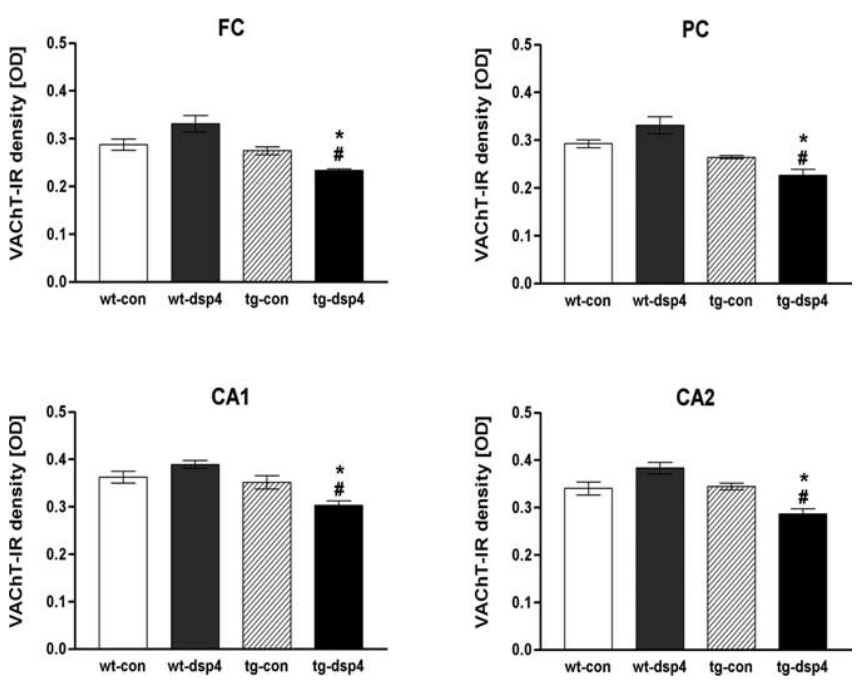

Figure 6. Changes of VAChT-IR indicate a loss of cholinergic boutons in NA-depleted APP23 mice. Cholinergic boutons were detected by VAChT-IR in the frontal cortex (FC), parietal cortex $(P C)$, and in two hippocampal regions (CA1, $C A 2)$. In all of the regions that were evaluated, no difference among wild-type controls (wt-con), NA-depleted wild-type mice (wt-dsp4), and saline-injected APP23 mice (tg-con) was detectable. However, APP23 mice with LC degeneration (tg-dsp4) had significantly fewer VAChT-positive cholinergic boutons compared with nontransgenic mice and with $\mathrm{tg}$-con (mean $\pm \mathrm{SEM} ; n=10$ animals per group; ANOVA, followed by Tukey's test). ${ }^{*} p<0.05$ for tg-dsp4 versus wt-dsp4/con; ${ }^{\#} p<0.05$ for tg-dsp4 versus tg-con.

To assess whether the iNOS was functional and forming NOdependent peroxynitrite, we stained sections from NA-depleted APP23 with a 3-NT antibody, which labels sites of peroxynitritemediated damage (Beckman and Koppenol, 1996). 3-NT immunostaining was detected in cerebral cortex and hippocampus, and an increased number of 3-NT-stained structures was observed in the vicinity of amyloid plaques compared with plaque-free regions. These results indicate elevated peroxynitrite formation at sites where cells with increased iNOS expression have been found (Fig. 5A). To determine additionally whether this NO-dependent peroxynitrite formation affects neurons, we performed confocal staining for NeuN and 3-NT, which showed neurons intensely stained for 3-NT (Fig. 5A). Quantification of 3-NT/NeuNcostained neurons additionally revealed that NA depletion potentiated neuronal 3-NT labeling at a distance of 26-75 $\mu \mathrm{m}$ from the plaque center (Fig. 5C). This is the same interval at which an increased number of acid fuchsin-labeled cells had been located (Fig. $4 B$ ).

\section{Decreased VAChT in LC projection areas}

Because previous data indicated that overexpression of mutant human APP alone does not affect the density of cholinergic synapses (Wong et al., 1999), we tested whether LC degeneration and subsequent alterations would influence the cholinergic system. Cholinergic terminals were stained immunoradiographically for the VAChT as previously described (Debeir et al., 1999). Because cholinergic innervation differs within cerebral cortex and hippocampus (Wong et al., 1999), smaller regions, including the frontal cortex, the parietal cortex, and the hippocampal CA1 and CA2 fields, were analyzed separately. NA depletion of wild-type controls did not change the density of VAChTimmunoreactive cholinergic boutons significantly (Fig. 6). Similarly, nonlesioned APP23 mice showed no changes in the VAChT density compared with nontransgenic controls. However, NA depletion of APP23 mice caused a significant decrease of VAChT density in all of the regions that were ana- lyzed (Fig. 6). In addition to these overall changes, the laminar distribution of the cholinergic synapses was evaluated. Laminas I, II/III, and V showed a significant decrease in NAdepleted APP23 mice, whereas lamina VI remained unaffected by NA depletion (data not shown). No VAChT staining was found in the paraventricular thalamus, in agreement with its very low cholinergic innervation in rodents (Levey et al., 1987).

\section{NA loss increases cognitive deficits in APP23 mice}

To determine whether NA depletion of APP23 mice affected their cognition, we analyzed these animals in different learning tests. The radial arm maze is a paradigm for spatial learning in which animals are trained to remember the location of a food reward. There was a clear difference in the performance between wildtype and APP23 mice injected with saline. Wild-type animals needed fewer trials to locate the food pellets $\left(F_{(3,455)}=13.175\right.$; $p<0.001)$, and they committed fewer working memory $\left(F_{(3,455)}\right.$ $=13.726 ; p<0.001)$ and reference memory errors $\left(F_{(3,455)}=\right.$ $10.582 ; p<0.001$ ) (Fig. 7A). NA depletion of control animals did not affect their performance in this test. However, NA-depleted transgenic mice needed significantly more trials and committed more working memory and reference memory errors in comparison to vehicle-treated transgenic mice.

The object recognition test evaluates the animals' ability to recognize a previously seen inanimate object. Wild-type mice and transgenic mice recognized the previously seen object, as indicated by a significant decrease in the preference ratio at the second presentation. APP23 mice treated with dsp4 showed a similar decrease, although it did not reach significance (Fig. 7B).

The partner recognition test is similar to the previous model, but the recognition of a previously seen partner is influenced more strongly by social and emotional cues. Strikingly, NAdepleted APP23 mice did not seem to recognize the partner they had seen $60 \mathrm{~min}$ before, whereas all other groups showed a clear reduction in the social interaction time at the second presentation (Fig. 7C). We also considered the possibility that the reduction in social activity might have resulted from a loss of interest or from exhaustion. Thus we tested these animals in a separate set of experiments in which we presented a new partner in the second session. The social activity was not reduced in any of the groups in the second session (data not shown), indicating that the previously seen decrease in social interaction was indeed attributable to partner recognition.

To test the nondeclarative memory, we studied habituation in the open field. Both horizontal $\left(F_{(2,54)}=148.46 ; p<0.001\right)$ and vertical $\left(F_{(2,54)}=119.86 ; p<0.001\right)$ activities significantly decreased in all groups during the repetitions, indicating a similar level of habituation (Fig. 7D). Transgenic mice were somewhat more active than controls (horizontal activity, $F_{(1,27)}=11.91$; $p<0.01$; vertical activity, $\left.F_{(1,27)}=10.71 ; p<0.01\right)$. No significant effect was seen by NA depletion in the horizontal activity $\left(F_{(1,27)}=3.55\right.$; not significant), whereas vertical activity was only marginally higher in all NA-depleted animals $\left(F_{(1,27)}=12.24 ; p<0.01\right)$.

\section{High-resolution-guided brain micro-PET analysis in APP23 mice}

Alzheimer's disease patients show a characteristic pattern of altered cerebral glucose metabolism, flumazenil binding, and acetylcholine esterase activity (Herholz et al., 2002). To test whether APP23 mice with or without LC degeneration show similar changes, we assessed the steady state of $\left[{ }^{18} \mathrm{~F}\right] \mathrm{FDG}$ uptake, 

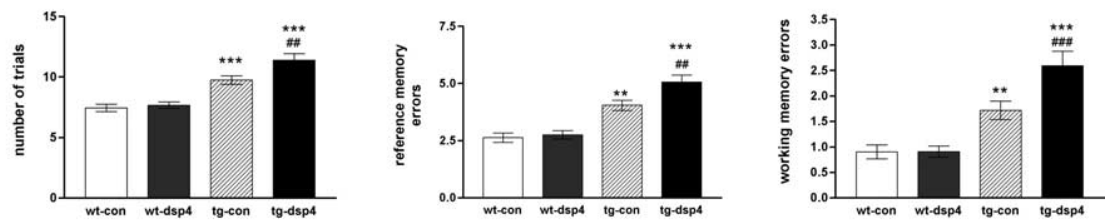

B
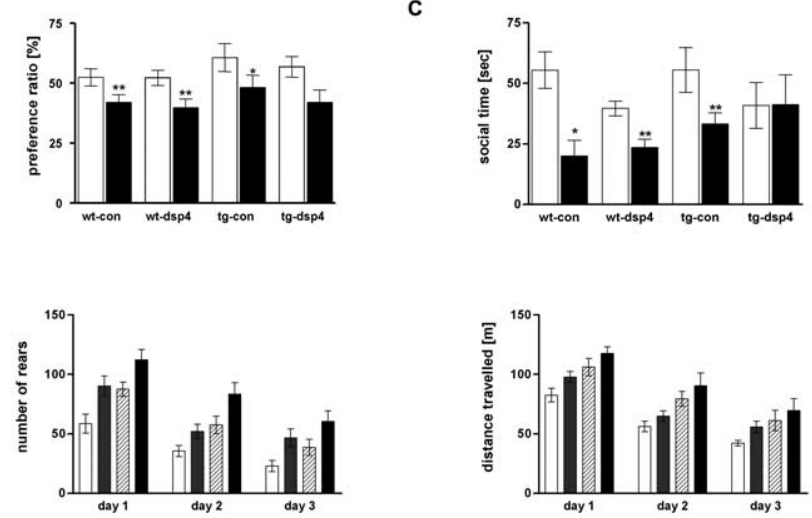

Figure 7. Behavior and cognition are affected by NA depletion of APP23 transgenic mice. $\boldsymbol{A}$, Radial arm maze test. APP23 mice (tg-con) needed more trials and committed more reference and working memory errors during the test compared with wild-type mice (wt-con). Dsp4 treatment in APP23 (tg-dsp4), but not in wild types (wt-dsp4), increased the number of total trials needed to complete the task as well as the number of reference and working memory errors (mean $\pm \mathrm{SEM} ; n=15$ animals per group; ANOVA, followed by Student's-Newman-Keuls test). ${ }^{* *} p<0.01 ;{ }^{* * *} p<0.001$ for tg-dsp4 versus wt-con; ${ }^{\# \#} p<0.01 ;{ }^{\# \# \#} p<$ 0.001 for $\mathrm{tg}$-dsp4 versus $\mathrm{tg}$-con. $\boldsymbol{B}, 0$ bject recognition test. Each group showed a comparable decrease in preference ratio in the second trial, although APP23 with a lesioned noradrenergic system just failed to reach the criterion level $\left(t_{(1,6)}=2.27 ; p=\right.$ 0.064). Open bars represent the first trial, and filled bars represent the second trial (mean \pm SEM; $n=6-10$; Student's $t$ test; $\left.{ }^{*} p<0.05 ;{ }^{* *} p<0.01\right)$. C, Social partner recognition test. Recognition results in a significant decrease in time spent in social interactions after presentation of the same partner twice with a $1 \mathrm{~h}$ interval. Time spent in social interaction did not change in transgenics with a lesioned noradrenergic system, showing lack of recognition, whereas other groups recognized the previously seen partner normally. Open bars represent the first presentation, and filled bars represent the second presentation (mean \pm SEM; $n=6-10$; Student's $t$ test; ${ }^{*} p<0.05 ;{ }^{* *} p<0.01$ comparing the first and second presentations). $\boldsymbol{D}$, Locomotor activity. The activity of saline-treated (open bar) and dsp4-treated (gray bar) wild-type mice as well as saline-treated (dashed bar) and dsp4-treated (black bar) APP23 was evaluated for $15 \mathrm{~min}$ in the open field in a low-aversive environment. Horizontal activity of transgenic mice was higher, but dsp4 treatment did not influence this parameter significantly. Both transgene expression as well as dsp4 treatment increased the vertical activity. A similar level of decrease in this parameter during the repetitions in each group suggests no differences in habituation (mean \pm SEM; $n=6-10$ ).

$\left[{ }^{11} \mathrm{C}\right]$ FMZ binding, and $\left[{ }^{11} \mathrm{C}\right] \mathrm{MP} 4 \mathrm{~A}$ trapping by micro-PET in vivo (Fig. 8). Because the cerebellum is innervated weakly by noradrenergic LC terminals, we used the cerebellum as a background control region for micro-PET evaluation. To ensure proper ROI placement within the cortex, we coregistered micro-PET images with high-resolution magnetic resonance images (Fig. 8). The $\left[{ }^{18} \mathrm{~F}\right] \mathrm{FDG},\left[{ }^{11} \mathrm{C}\right] \mathrm{FMZ}$, and $\left[{ }^{11} \mathrm{C}\right] \mathrm{MP} 4 \mathrm{~A}$ cortex-to-cerebellum ratios were not significantly different between APP23 and nontransgenic mice under basal conditions and during aging (Fig. $8 \mathrm{~B}$ ). However, as soon as 4 weeks after dsp4 treatment, a significant decrease of flumazenil binding and acetylcholine esterase activity was found between dsp4-treated and nontreated APP23 mice. At 3 months after noradrenergic depletion significant differences were apparent for all three parameters that were evaluated (Fig. 8 A, C). No changes were observed by dsp 4 treatment of littermate controls. These data indicate that either $\mathrm{A} \beta$ deposition or NA depletion alone did not lead to significant alterations of these metabolic parameters. Together, however, they caused a significant alteration of cerebral glucose metabolism, neuronal integrity, as well as acetylcholine esterase activity as assessed by multi-tracer micro-PET in vivo.

\section{Discussion}

LC degeneration is a well known feature of $\mathrm{AD}$ (Forno, 1966) and correlates with its clinical and histopathological changes (Bondareff et al., 1987; Zarow et al., 2003). Loss of LC neurons occurs early in AD (German et al., 1992) and subsequently attenuates the allocation of NA to respective projection areas (Adolfsson et al., 1979; Mann et al., 1980). Using amyloid plaquecontaining APP transgenic mice (APP23), we show that LC degeneration and the resulting NA depletion increase inflammation and amyloid plaque formation. Furthermore, NA depletion in combination with amyloid deposits leads to a decrease in neuron number and in neuronal function as determined by micro-PET and behavioral studies in vivo. Our results indicate that LC degeneration may contribute significantly to the pathogenesis of AD.

In addition to its function as a classical neurotransmitter, NA exerts potent antiinflammatory effects in the brain (for review, see Feinstein et al., 2002). Consistent with this notion, we found that LC degeneration increased the number of activated microglia and hypertrophic astrocytes in cortical and hippocampal projection areas. In support of the specificity, no such increase was apparent in the paraventricular thalamus, which does not receive NA innervation from the LC (Foote et al., 1983). Elevated inflammation was present only in transgenic animals carrying an amyloid burden, whereas wild-type animals did not show much change with NA depletion, indicating that amyloid was required as triggering cofactor. These observations are consistent with the view that NA functions as an endogenous immunosuppressor counteracting the amyloid-induced inflammation. This notion also is supported by our previous demonstration that acute $\mathrm{A} \beta$ brain injection increases inflammatory mRNA transcripts. Dsp4 lesioning enhances this inflammatory response, although it is reversed partially by NA treatment (Heneka et al., 2002). In the current long-term study NA depletion also elevated the amyloid plaque load in affected projection areas. Although this increase might be secondary to the elevated inflammation state, which could increase A $\beta$ generation (Blasko et al., 1999; Sastre et al., 2003), it seems possible as well that it occurs by an independent, more direct mechanism. In this case the increase in amyloid may contribute to increased inflammation. A relationship between default neuronal activity and $\mathrm{A} \beta$ generation in vitro as well as amyloid deposition in human brain has been described recently (Kamenetz et al., 2003; Buckner et al., 2005). Although NA depletion is not expected to lead directly to increased activity, complex long-term compensatory mechanisms cannot be excluded. In any event, our data clearly show that LC degeneration and the resulting NA depletion in APP transgenic mice enhance these two important pathological AD characteristics.

Increased amyloid load and inflammation were accompanied 
by a significant reduction in neuron number in affected brain regions of APP23 mice, although LC degeneration did not alter neuron numbers in nontransgenic mice. Nonlesioned APP23 mice showed only a minor neuronal decrease, as previously reported (Calhoun et al., 1998; Bondolfi et al., 2002). The reduction in neuron number was paralleled by the occurrence of acid fuchsin-labeled neurons, a marker of neuronal degeneration (Kiernan et al., 1998). Labeling of damaged cells strongly increased in APP23 transgenics compared with nontransgenic littermates but was even higher after noradrenergic depletion. Acid fuchsin-labeled neurons appeared mostly at the plaque periphery of APP23 mice. NA depletion increased the number of acid fuchsin-labeled neurons in a distinct corridor surrounding the plaques, indicating that the observed increase in cell degeneration is directly or indirectly dependent on the amyloid deposits.

Consistent with previous observations in rats (Heneka et al., 2002), NA depletion increased iNOS expression in astrocytes and neurons as well as 3-nitrotyrosine staining, a measure of NO-mediated peroxynitrite formation, in close proximity to amyloid plaques in APP23 mice. iNOS expression and NO-mediated peroxynitrite formation has been described in $\mathrm{AD}$ (Vodovotz et al., 1996; Smith et al., 1997). Of note, peroxynitrite is a free radical with high cell toxicity (Beckman and Koppenol, 1996), and increased peroxynitrite there-

fore may account for the observed neuronal death. However, other radicals and mechanisms, such as direct amyloid or cytokine toxicity, may contribute alone or together to neuronal degeneration.

Previous work with APP23 and other APP transgenic mice indicated only small alterations of the cholinergic system in very old mice (Wong et al., 1999; Boncristiano et al., 2002). We confirmed these data by using immunoradiographic labeling of the vesicular acetylcholine transporter, which marks cholinergic boutons in the cortex and hippocampus. NA depletion of APP23 mice decreased the density of cholinergic boutons significantly, whereas depletion of nontransgenic littermates had no effect, emphasizing the importance of concurrent amyloid pathology. These data suggest that LC degeneration may contribute to cholinergic deficits in AD. Interestingly, amyloid levels remain relatively unchanged after cholinergic basal forebrain degeneration, indicating that cholinergic denervation does not affect amyloid deposition (Boncristiano et al., 2002). Although both the cholinergic and the noradrenergic system are decreasing early in $\mathrm{AD}$, only NA depletion seems to promote amyloidosis.

Histopathological consequences of NA depletion also are reflected in functional changes in the brain. We used micro-PET to assess brain metabolism and function in mice and to allow for a comparison with similar PET data in AD patients. PET is being used in the differential diagnosis of dementias and currently is being explored for early disease detection. Changes in brain glucose metabolism by $\left[{ }^{18} \mathrm{~F}\right] \mathrm{FDG}$-PET alone can distinguish $\mathrm{AD}$ patients from age-matched controls with high sensitivity (93\%) and specificity (93\%) (Herholz et al., 2002). With the use of this tracer no apparent differences between APP23 mice and their lesioned or nonlesioned littermate controls were detected. A small reduction in neuronal glucose metabolism might be expected, based on the neural loss and the behavioral changes that were observed. However, animal PET may not be sufficiently sensitive to detect such small changes, or it may have been compensated for by increased gliosis. NA-depleted APP23 mice, however, could be distinguished clearly, confirming their enhanced brain pathology on a functional level. Similar results were obtained by using neuronal tracers: $\left[{ }^{11} \mathrm{C}\right] \mathrm{FMZ}$, a ligand that selectively binds to the central benzodiazepine receptor in the neuronal membrane serves as surrogate marker for neuronal integrity (Heiss et al., 1997), and $\left[{ }^{11} \mathrm{C}\right] \mathrm{MP} 4 \mathrm{~A}$, measuring acetylcholine esterase activity, is reduced early in the neocortex of $\mathrm{AD}$ patients (Iyo et al., 1997). These results indicate that noradrenergic depletion of APP23 mice causes significant changes in neuronal integrity and in cholinergic function, which are absent with either lesion alone. These alterations in vivo are in good correspondence to the detection of increased neuronal damage and reduced number of cholinergic boutons.

The pathological alterations observed in APP23 brain in response to LC degeneration also resulted in behavioral changes and deteriorated memory capabilities. When analyzed in the eight arm radial maze learning and memory test, APP23 mice with intact noradrenergic innervation showed an increased num- 
ber of working and reference memory errors compared with nontransgenic littermates. NA depletion did not affect nontransgenic animals, indicating that it is not sufficient to induce these behavioral alterations and memory deficits, as previously suggested (Sirvio et al., 1994; Lapiz et al., 2001). In contrast, NA-depleted APP23 mice showed a robust and significant increase in all radial arm maze parameters, committing significantly more working and reference memory errors than nondepleted APP23 mice. In addition, dsp4-lesioned APP23 mice completely lost the ability to recognize a social partner, reminiscent of the clinical picture of AD patients. Nevertheless, their memory deficits were not generalized, because no or only a very minor effect was detected in the object recognition test. The enhanced memory deficits observed in our studies may be attributable to the increased neuron damage and loss. However, cytokines, NO, and $\mathrm{A} \beta$ reportedly decrease hippocampal long-term potentiation, which is thought to play a key role in consolidation of memory (Murray and Lynch, 1998; Chapman et al., 1999; Wang et al., 2004). Accordingly, both increased microglial activation and elevated $\mathrm{A} \beta$ levels might contribute directly to cognitive dysfunction. In this regard, it seems noteworthy that a plasticity-enhancing role for NA has been demonstrated in hippocampal long-term potentiation (Stanton and Sarvey, 1987; Hopkins and Johnston, 1988; Izumi and Zorumski, 1999), suggesting that decreased NA may impair memory functions synergistically with raised levels of $A \beta$ and inflammatory mediators.

In APP23 mice no significant changes of the LC are apparent, suggesting that this $\mathrm{AD}$ model, although mimicking effects of hippocampal and cortical amyloid deposition, does not display degeneration of aminergic brainstem nuclei. Induction of LC degeneration resulted in dramatic loss of NA in projection areas, enhanced AD-like pathology, and decreased neuronal function and cognitive performance. Although amyloid deposits were required for this augmentation, NA depletion also enhanced amyloid deposition, illustrating the interaction of both pathologies. Therefore, early LC degeneration and NA depletion in AD (German et al., 1992) may contribute to AD pathogenesis by mechanisms described in this study. However, it has to be considered that LC neurons generate several other substances, including neurotensin, vasoactive intestinal peptide, atrial natriuretic factor, and fibroblast growth factor 2 (Marien et al., 2004), which also may contribute to neuroinflammatory and degenerative changes in LC projection areas. A partial reversal by NA treatment of the increased brain inflammation after acute LC depletion and $\mathrm{A} \beta$ injection (Heneka et al., 2002) argues for a role of NA, yet it remains to be shown that NA treatment also reverses the elevation of amyloid deposition. Future studies are needed to compare treatments increasing NA or other LC neuron products with respect to potential beneficial effects in $\mathrm{AD}$ models with LC degeneration.

\section{References}

Adolfsson R, Gottfries CG, Roos BE, Winblad B (1979) Changes in the brain catecholamines in patients with dementia of Alzheimer type. Br J Psychiatry 135:216-223.

Akiyama H, Barger S, Barnum S, Bradt B, Bauer J, Cole GM, Cooper NR, Eikelenboom P, Emmerling M, Fiebich BL, Finch CE, Frautschy S, Griffin WS, Hampel H, Hull M, Landreth G, Lue L, Mrak R, Mackenzie IR, McGeer PL, et al. (2000) Inflammation and Alzheimer's disease. Neurobiol Aging 21:383-421.

Beckman JS, Koppenol WH (1996) Nitric oxide, superoxide, and peroxynitrite: the good, the bad, and ugly. Am J Physiol 271:C1424-C1437.

Bezin L, Marcel D, Rousset C, Pujol JF, Weissmann D (1994) Quantitative study of tyrosine hydroxylase protein levels within the somatic area of the rat locus coeruleus during postnatal development. J Neurosci $14: 7502-7510$.

Blasko I, Marx F, Steiner E, Hartmann T, Grubeck-Loebenstein B (1999) TNF $\alpha$ plus IFN $\gamma$ induce the production of Alzheimer $\beta$-amyloid peptides and decrease the secretion of APPs. FASEB J 13:63-68.

Boncristiano S, Calhoun ME, Kelly PH, Pfeifer M, Bondolfi L, Stalder M, Phinney AL, Abramowski D, Sturchler-Pierrat C, Enz A, Sommer B, Staufenbiel M, Jucker M (2002) Cholinergic changes in the APP23 transgenic mouse model of cerebral amyloidosis. J Neurosci 22:3234-3243.

Bondareff W, Mountjoy CQ, Roth M, Rossor MN, Iversen LL, Reynolds GP, Hauser DL (1987) Neuronal degeneration in locus ceruleus and cortical correlates of Alzheimer disease. Alzheimer Dis Assoc Disord 1:256-262.

Bondolfi L, Calhoun M, Ermini F, Kuhn HG, Wiederhold KH, Walker L, Staufenbiel M, Jucker M (2002) Amyloid-associated neuron loss and gliogenesis in the neocortex of amyloid precursor protein transgenic mice. J Neurosci 22:515-522.

Buckner RL, Snyder AZ, Shannon BJ, LaRossa G, Sachs R, Fotenos AF, Sheline YI, Klunk WE, Mathis CA, Morris JC, Mintun MA (2005) Molecular, structural, and functional characterization of Alzheimer's disease: evidence for a relationship between default activity, amyloid, and memory. J Neurosci 25:7709-7717.

Busser J, Geldmacher DS, Herrup K (1998) Ectopic cell cycle proteins predict the sites of neuronal cell death in Alzheimer's disease brain. J Neurosci 18:2801-2807.

Calhoun ME, Wiederhold KH, Abramowski D, Phinney AL, Probst A, Sturchler-Pierrat C, Staufenbiel M, Sommer B, Jucker M (1998) Neuron loss in APP transgenic mice. Nature 395:755-756.

Chapman PF, White GL, Jones MW, Cooper-Blacketer D, Marshall VJ, Irizarry M, Younkin L, Good MA, Bliss TV, Hyman BT, Younkin SG, Hsiao KK (1999) Impaired synaptic plasticity and learning in aged amyloid precursor protein transgenic mice. Nat Neurosci 2:271-276.

Debeir T, Saragovi HU, Cuello AC (1999) A nerve growth factor mimetic TrkA antagonist causes withdrawal of cortical cholinergic boutons in the adult rat. Proc Natl Acad Sci USA 96:4067-4072.

Dudley MW, Howard BD, Cho AK (1990) The interaction of the $\beta$-haloethyl benzylamines, xylamine, and DSP-4 with catecholaminergic neurons. Annu Rev Pharmacol Toxicol 30:387-403.

Feinstein DL, Heneka MT, Gavrilyuk V, Dello RC, Weinberg G, Galea E (2002) Noradrenergic regulation of inflammatory gene expression in brain. Neurochem Int 41:357-365.

Foote SL, Bloom FE, Aston-Jones G (1983) Nucleus locus ceruleus: new evidence of anatomical and physiological specificity. Physiol Rev 63:844-914.

Forno LS (1966) Pathology of parkinsonism. J Neurosurg 266-271.

Forstl H, Levy R, Burns A, Luthert P, Cairns N (1994) Disproportionate loss of noradrenergic and cholinergic neurons as cause of depression in Alzheimer's disease-a hypothesis. Pharmacopsychiatry 27:11-15.

Fritschy JM, Grzanna R (1989) Immunohistochemical analysis of the neurotoxic effects of DSP-4 identifies two populations of noradrenergic axon terminals. Neuroscience 30:181-197.

Frohman EM, Vayuvegula B, Gupta S, van den Noort S (1988) Norepinephrine inhibits $\gamma$-interferon-induced major histocompatibility class II (Ia) antigen expression on cultured astrocytes via $\beta 2$-adrenergic signal transduction mechanisms. Proc Natl Acad Sci USA 85:1292-1296.

German DC, Manaye KF, White III CL, Woodward DJ, McIntire DD, Smith WK, Kalaria RN, Mann DM (1992) Disease-specific patterns of locus coeruleus cell loss. Ann Neurol 32:667-676.

Harro J, Pahkla R, Modiri A-R, Harro M, Kask A, Oreland L (1999) Dosedependent effects of noradrenergic denervation by DSP-4 treatment on forced swimming and $\beta$-adrenoceptor binding in the rat. J Neural Transm 106:619-629.

Heiss WD, Graf R, Fujita T, Ohta K, Bauer B, Lottgen J, Wienhard K (1997) Early detection of irreversibly damaged ischemic tissue by flumazenil positron emission tomography in cats. Stroke 28:2045-2051.

Heneka MT, Galea E, Gavriluyk V, Dumitrescu-Ozimek L, Daeschner J, O’Banion MK, Weinberg G, Klockgether T, Feinstein DL (2002) Noradrenergic depletion potentiates $\beta$-amyloid-induced cortical inflammation: implications for Alzheimer's disease. J Neurosci 22:2434-2442.

Herholz K, Salmon E, Perani D, Baron JC, Holthoff V, Frolich L, Schonknecht P, Ito K, Mielke R, Kalbe E, Zundorf G, Delbeuck X, Pelati O, Anchisi D, Fazio F, Kerrouche N, Desgranges B, Eustache F, Beuthien-Baumann B, 
Menzel C, et al. (2002) Discrimination between Alzheimer dementia and controls by automated analysis of multicenter FDG PET. NeuroImage 17:302-316.

Hopkins WF, Johnston D (1988) Noradrenergic enhancement of long-term potentiation at mossy fiber synapses in the hippocampus. J Neurophysiol 59:667-687.

Hu XX, Goldmuntz EA, Brosnan CF (1991) The effect of norepinephrine on endotoxin-mediated macrophage activation. J Neuroimmunol 31:35-42.

Iyo M, Namba H, Fukushi K, Shinotoh H, Nagatsuka S, Suhara T, Sudo Y, Suzuki K, Irie T (1997) Measurement of acetylcholinesterase by positron emission tomography in the brains of healthy controls and patients with Alzheimer's disease. Lancet 349:1805-1809.

Izumi Y, Zorumski CF (1999) Norepinephrine promotes long-term potentiation in the adult rat hippocampus in vitro. Synapse 31:196-202.

Kamenetz F, Tomita T, Hsieh H, Seabrook G, Borchelt D, Iwatsubo T, Sisodia S, Malinow R (2003) APP processing and synaptic function. Neuron 37:925-937.

Kiernan JA, MacPherson CM, Price A, Sun T (1998) A histochemical examination of the staining of kainate-induced neuronal degeneration by anionic dyes. Biotech Histochem 73:244-254.

Lapiz MD, Mateo Y, Durkin S, Parker T, Marsden CA (2001) Effects of central noradrenaline depletion by the selective neurotoxin DSP-4 on the behaviour of the isolated rat in the elevated plus maze and water maze. Psychopharmacology (Berl) 155:251-259.

Levey AI, Hallanger AE, Wainer BH (1987) Choline acetyltransferase immunoreactivity in the rat thalamus. J Comp Neurol 257:317-332.

Luth HJ, Holzer M, Gartner U, Staufenbiel M, Arendt T (2001) Expression of endothelial and inducible NOS isoforms is increased in Alzheimer's disease, in APP23 transgenic mice and after experimental brain lesion in rat: evidence for an induction by amyloid pathology. Brain Res 913:57-67.

Mann DM, Lincoln J, Yates PO, Stamp JE, Toper S (1980) Changes in the monoamine-containing neurones of the human CNS in senile dementia. Br J Psychiatry 136:533-541.

Marien MR, Colpaert FC, Rosenquist AC (2004) Noradrenergic mechanisms in neurodegenerative diseases: a theory. Brain Res Brain Res Rev 45:38-78.

Matthews KL, Chen CP, Esiri MM, Keene J, Minger SL, Francis PT (2002) Noradrenergic changes, aggressive behavior, and cognition in patients with dementia. Biol Psychiatry 51:407-416.

Murchison CF, Zhang XY, Zhang WP, Ouyang M, Lee A, Thomas SA (2004) A distinct role for norepinephrine in memory retrieval. Cell 117:131-143.

Murray CA, Lynch MA (1998) Evidence that increased hippocampal expression of the cytokine interleukin- $1 \beta$ is a common trigger for age- and stress-induced impairments in long-term potentiation. J Neurosci 18:2974-2981.

Ohno M, Yoshimatsu A, Kobayashi M, Watanabe S (1997) Noradrenergic DSP-4 lesions aggravate impairment of working memory produced by hippocampal muscarinic blockade in rats. Pharmacol Biochem Behav $57: 257-261$

Olton DS (1987) The radial arm maze as a tool in behavioral pharmacology. Physiol Behav 40:793-797.

Paxinos G, Franklin K (2001) The mouse brain in stereotaxic coordinates. San Diego: Academic.

Sastre M, Dewachter I, Landreth GE, Willson TM, Klockgether T, Van Leuven F, Heneka MT (2003) Nonsteroidal anti-inflammatory drugs and peroxisome proliferator-activated receptor- $\gamma$ agonists modulate immunostimulated processing of amyloid precursor protein through regulation of $\beta$-secretase. J Neurosci 23:9796-9804.

Schubert M, Gautam D, Surjo D, Ueki K, Baudler S, Schubert D, Kondo T, Alber J, Galldiks N, Kustermann E, Arndt S, Jacobs AH, Krone W, Kahn CR, Bruning JC (2004) Role for neuronal insulin resistance in neurodegenerative diseases. Proc Natl Acad Sci USA 101:3100-3105.

Sirvio J, Lahtinen H, Riekkinen Jr P, Riekkinen PJ (1994) Spatial learning and noradrenaline content in the brain and periphery of young and aged rats. Exp Neurol 125:312-315.

Smith MA, Richey Harris PL, Sayre LM, Beckman JS, Perry G (1997) Widespread peroxynitrite-mediated damage in Alzheimer's disease. J Neurosci 17:2653-2657.

Stanton PK, Sarvey JM (1987) Norepinephrine regulates long-term potentiation of both the population spike and dendritic EPSP in hippocampal dentate gyrus. Brain Res Bull 18:115-119.

Sturchler-Pierrat C, Abramowski D, Duke M, Wiederhold KH, Mistl C, Rothacher S, Ledermann B, Burki K, Frey P, Paganetti PA, Waridel C, Calhoun ME, Jucker M, Probst A, Staufenbiel M, Sommer B (1997) Two amyloid precursor protein transgenic mouse models with Alzheimer disease-like pathology. Proc Natl Acad Sci USA 94:13287-13292.

Vodovotz Y, Lucia MS, Flanders KC, Chesler L, Xie QW, Smith TW, Weidner J, Mumford R, Webber R, Nathan C, Roberts AB, Lippa CF, Sporn MB (1996) Inducible nitric oxide synthase in tangle-bearing neurons of patients with Alzheimer's disease. J Exp Med 184:1425-1433.

Wang Q, Rowan MJ, Anwyl R (2004) $\beta$-Amyloid-mediated inhibition of NMDA receptor-dependent long-term potentiation induction involves activation of microglia and stimulation of inducible nitric oxide synthase and superoxide. J Neurosci 24:6049-6056.

Willis SA, Nisen PD (1995) Inhibition of lipopolysaccharide-induced IL-1 $\beta$ transcription by cyclic adenosine monophosphate in human astrocytic cells. J Immunol 154:1399-1406.

Wong TP, Debeir T, Duff K, Cuello AC (1999) Reorganization of cholinergic terminals in the cerebral cortex and hippocampus in transgenic mice carrying mutated presenilin-1 and amyloid precursor protein transgenes. J Neurosci 19:2706-2716.

Zarow C, Lyness SA, Mortimer JA, Chui HC (2003) Neuronal loss is greater in the locus coeruleus than nucleus basalis and substantia nigra in Alzheimer and Parkinson diseases. Arch Neurol 60:337-341. 